\title{
CASEBOOK ON GENERAL MANAGEMENT IN ASIA PACIFIC
}

Edited by

Dominique Turpin and Xiaobai Shen

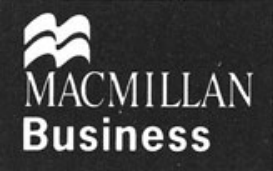


Selection and editorial matter

Copyright IMD - International Institute for Management Development, Lausanne, Switzerland 1999

Cases copyright before 1990:

Copyright 1999 by IMEDE, Lausanne, Switzerland. IMD - International Institute for Management Development, resulting from the merger between IMEDE, Lausanne, and IMI, Geneva, acquires and retains all rights. Not to be used or reproduced without written permission directly from IMD.

Cases copyright after 1990:

Copyright 1999 by IMD - International Institute for Management Development, Lausanne, Switzerland. Not to be used or reproduced without written permission directly from IMD.

All rights reserved. No reproduction, copy or transmission of this publication may be made without written permission.

No paragraph of this publication may be reproduced, copied or transmitted save with written permission or in accordance with the provisions of the Copyright, Designs and Patents Act 1988, or under the terms of any licence permitting limited copying issued by the Copyright Licensing Agency, 90 Tottenham Court Road, London W1P 9HE.

Any person who does any unauthorised act in relation to this publication may be liable to criminal prosecution and civil claims for damages.

The authors have asserted their right to be identified as the authors of this work in accordance with the Copyright, Designs and Patents Act 1988.

First published 1999 by

MACMILLAN PRESS LTD

Houndmills, Basingstoke, Hampshire RG21 6XS

and London

Companies and representatives throughout the world

ISBN 978-0-333-71792-9 ISBN 978-1-349-27474-1 (eBook)

DOI 10.1007/978-1-349-27474-1

A catalogue record for this book is available from the British Library.

This book is printed on paper suitable for recycling and made from fully managed and sustained forest sources.

$$
\begin{array}{rrrrrrrrrr}
10 & 9 & 8 & 7 & 6 & 5 & 4 & 3 & 2 & 1 \\
08 & 07 & 06 & 05 & 04 & 03 & 02 & 01 & 00 & 99
\end{array}
$$

Typeset in Great Britain by Aarontype Ltd

Easton, Bristol 


\section{Contents}

Preface v

Acknowledgements vi

List of Cases vii

Notes on the Editors ix

Introduction: Why is Asia Pacific the Focus of Attention in the Business World Today? xi

PART ONE: WESTERN BUSINESSES IN ASIA PACIFIC 1 Introduction 3

1. New Potential in Asia Pacific 7

Case 1.1 Potain S.A.

Case 1.2 Nestlé in ASEAN

2. Competing in Deregulated Markets 61

Case 2.1 Philip Morris K.K.

3. Dealing with Cross-cultural Issues 93

Case 3.1 Lestra Design

Case 3.2 Delissa in Japan

4. Managing Labour Relations 127

Case 4.1 Ace Electronics Korea, Ltd.

5. Managing Crisis and Ethical Problems 143

Case 5.1 Lussman-Shizuka Corp.

Case 5.2 Chen \& Liew Ltd.

6. Strategic Planning for External Environmental Changes 151 Case 6.1 Ciba in China

7. Implementing Global Strategies in Asia 171

Case 7.1 Hilti Corporation

PART TWO: ASIAN BUSINESSES IN ASIA PACIFIC 181

Introduction 183

8. Domestic Competition in Japan 187

Case 8.1 Sanraku Inc.

Case 8.2 Konica Corp.

Case 8.3 Kirin Brewery Co., Ltd. - The Dry Beer War 
9. Competing in the Asia-Pacific Region 251

Cases 9.1A-F Hong Kong \& Shenzhen Bank

Case 9.2 The Matsushita Group in Malaysia

Case 9.3 Malaysian Airline System - Flying into the Future

Case 9.4 China's XFM Project

Case 9.5 FoodWorld Supermarkets in India

\section{PART THREE: ASIAN BUSINESSES IN GLOBAL COMPETITION 397}

Introduction 399

10. From Internal Management Excellence to International Business Competencies 403

Case 10.1 Matsushita Electric Industrial Co.

Case $10.2 \mathrm{Kao}$ in Singapore

11. Competing in the World Market with Information Technology 445

Case 11.1 Singapore Airlines: Using Technology for Service Excellence

Case 11.2 Sony Manufacturing Company UK (Bridgend Colour Television Operation) - Appropriate Use of Information and Technology in Manufacturing

Case 11.3 Sony Barcelona - Achieving World-Class Product and Market Quality through Strategic Information Management

12. Finding Complementary Competencies - Managing Business in Europe through Alliances and Partnership 507

Case 12.1 Canon in the European Copier Market

Case 12.2 Olivetti in the European Copier Market

Case 12.3 The European Copier Industry

13. Competing in COMECON Countries 557

Case 13.1 Sony in Poland

14. Shifting from National to Regional Organization Structure $\mathbf{5 7 7}$

Case 14.1 Matsushita Electric Industrial Ltd. Europe - Sales and Marketing, 1994

Index 591 


\section{Preface}

In recent years, demands from IMD's business partners and the sponsors of IMD management programmes, particularly those concerned with international business and Asian countries, have been increasing. In a survey we recently conducted, companies list 'international' and 'Asia' as high priority topics. During the last few years, IMD faculty members have produced a range of cases about businesses operating in the Asia-Pacific region or about Asian businesses expanding to the rest of the world.

The cases in this book do not cover international management topics or look at the Asia-Pacific nations exhaustively. They are not intended to be examples of 'best practices' (or of ineffective management). We selected them for their general interest and pedagogic value, the overall picture of doing business in Asia that they paint, and the specific issues on management across cultures and nations that they present. The business world has already shown a keen interest in these issues. We believe this interest will grow. The cases are based on our personal observations of companies and their operation in countries where the IMD faculty has done consulting or research.

This 'Asia casebook' is primarily designed for general management teaching purposes, particularly in the field of international management. We have used every case at IMD successfully with both MBA participants and executives. Taken together, they cover management subjects in human resources, corporate culture, strategy, cross-cultural marketing, marketing, manufacturing, alliances and partnership, information technologies, and strategy.

Almost all the cases in this book are comprehensive. They contain selected information about the companies, and the events and circumstances they operate in. This may include detailed characterizations of particular managers or accounts of their experiences. It may also include the region's history and broader descriptions of the global economic, political and social situation, always linked to the particular managerial circumstances and/or the particular company. Cases are especially designed for teaching - they highlight the issues important in developing a management framework by engaging participants in probing discussions.

Most important, this book features cross-cultural and cross-national issues. The cases furnish vital background materials on the economic, political and social environment in the Asia-Pacific countries, together with more detailed notes on industrial sectors, market segments, consumer behaviour, etc. In addition, the views of the managers and the experiences of the companies, different as they are from each other and from those of economists and scholars, are invaluable because they are based on experience in the field. After all, whether the managers or the companies in the cases have failed or succeeded, their firsthand experience is invaluable. One of the lessons is this: good management in Asia may not be much different from good management anywhere else!

Dominique TuRpin AND Xiaobai Shen 


\section{Acknowledgements}

The editors would like to thank Professor Peter Lorange, President of IMD, Professor Phil Rosenzweig, Director of Research at IMD, Persita Egeli-Farmanfarma, IMD Case Administrator, Gordon Adler, IMD Senior Writer, Cheryl Petroski and Tessa Rowland for providing us with the resources necessary to put this book together. Our thanks also go to Professors Francis Bidault, Bob Collins, Jim Ellert, Pierre Goetschin, Song-Hyon Jang, Per Jenster, Vijay Jolly, Peter Killing, Jan Kubes, Nirmalya Kumar, Christopher Lovelock, Don Marchand, Phil Rosenzweig, Ser Toh Thian, George Taucher and Sandra Vandermerwe and Research Associates for contributing cases and teaching notes, and to the other IMD faculty members and research associates for their assistance and support. Last but not least, we would like to express our appreciation to our families: Minako, HélèneMiyuki, Antoine-Akio, Léo-Yukio and Ben for their extended support in the completion of this project.
The editors and publisher would like to thank the following for permission to use copyright material: Business Times (Malaysia) for statistics from Business Times; Economic Information \& Agency for statistics from the China Statistical Yearbook; The Economist Newspaper Limited for a chart from the article 'America's Empire Strikes Back', The Economist, 22 February 1992; Financial Times for the historical maps of Poland from Financial Times, 3 May 1991; InfoSource Management Services for statistics; Official Journal of the European Communities, L239, 26.8.1986, for statistics; Screen Digest for statistics from Screen Digest, March 1993; Sweet \& Maxwell Asia for statistics from The China Investment Guide, 3rd edn.

Every effort has been made to trace copyright holders, but if any have been inadvertently overlooked the publisher will be pleased to make the necessary arrangement at the first opportunity. 


\section{List of Cases}

\section{Global Strategy}

Case 1.2: Nestlé in ASEAN

Case 6.1: Ciba in China

Case 7.1: Hilti Corporation

Case 9.4: China's XFM Project

Case 10.2: Kao in Singapore

Case 12.1: Canon in the European Copier Market

Case 13.1: Sony in Poland

\section{Marketing Strategy}

Case 2.1: Philip Morris K.K.

Case 3.1: Lestra Design

Case 8.2: Konica Corp.

Case 8.3: Kirin Brewery Co., Ltd. - The Dry Beer War

Cases 9.1A-F: Hong Kong \& Shenzhen Bank

Case 9.5: FoodWorld Supermarkets in India

Case 14.1: Matsushita Electric Industrial Ltd. Europe - Sales and Marketing, 1994

\section{Cross-cultural Management}

Case 3.1: Lestra Design

Case 3.2: Delissa in Japan

Case 5.1: Lussman-Shizuka Corp.

Case 10.1: Matsushita Electric Industrial Co.

Case 10.2: Kao in Singapore

\section{Managing Information Technology}

Case 11.1: Singapore Airlines

Case 11.2: Sony Manufacturing Company UK

Case 11.3: Sony Barcelona

\section{Organization and Human Resource Management}

Case 3.2: Delissa in Japan

Case 4.1: Ace Elecronics Korea, Ltd.

Case 5.1: Lussman-Shizuka Corp.

Case 5.2: Chen \& Liew Ltd. 
Case 8.1: Sanraku Inc.

Cases 9.1A-F: Hong Kong \& Shenzhen Bank

Case 10.1: Matsushita Electric Industrial Co.

Case 14.1: Matsushita Electric Industrial Ltd. Europe - Sales and Marketing, 1994

\section{Alliances and Technology Transfer}

Case 1.1: Potain S.A.

Case 12.1: Canon in the European Copier Market 


\section{Notes on the Editors}

\section{Dominique V. Turpin}

Professor Turpin is a full-time faculty member of IMD (International Institute for Management Development) in Lausanne, Switzerland, and the Director of the IMD 'Master for Business Administration' (MBA) Programme. Dr Turpin is also director of several IMD executive programmes in Europe and Asia. He was previously director of another IMD executive programme entitled: 'Managing for Marketing Success' (1992-6). Dr Turpin has extensive experience in teaching, research and consultancy in the areas of marketing and international strategy in Europe, the Americas and Asia. Prior to joining IMD, he spent six years in Tokyo as representative of a French firm in Japan.

A French citizen, Dominique Turpin received his masters degree from ESSCA in France. He earned a doctoral degree in economics from Sophia University in Tokyo. His research has been widely published in more than fifty books, articles and case studies. Professor Turpin has been a regular contributor to Nihon Sangyo Shimbun (The Japan Industrial Journal), one of the leading business dailies in Japan. He is also the Continental Europe Editor for the Long Range Planning Journal, the international journal of strategic manage- ment, and sits on the board of one of the largest Japanese firms.

Since 1990, Professor Turpin has been a Director of the Board of the 'Japan Strategic Management Society'. Dr Turpin is a partner in Strategic Management International, Tokyo and a member of the 'Who's Who in Asian Studies', Geneva. Since 1994, Professor Turpin has also served as the IMD representative on the Academic Council of the China-Europe International Business School in Shanghai (People's Republic of China).

\section{Xiaobai Shen, Ph.D., M.Phil., B.Sc.}

Xiaobai Shen is currently a consultant for China-related business in Edinburgh. She came to Britain in 1991 to take her doctoral programme in the University of Edinburgh, and worked as research fellow in IMD (the International Institute for Management Development) in Lausanne, Switzerland.

In her previous career in China, Xiaobai Shen spent five years working in manufacturing industry during the Cultural Revolution. Her interests in telecommunications technology date back to her undergraduate study and subsequent teaching experience in Telecommunications Engineering in 
Shanghai Railway University. How- to young managers in Shanghai indusever, she became increasingly inter- tries. She then moved to Beijing to take ested in the social and economic an M.Phil. in Science \& Technology dimensions of technological change Policy, at the Chinese Academy of and the need to improve manage- Social Sciences, and worked for several ment methods for economic reform. years as a Research Fellow in the China Thus she was among those who ac- Research Institute for Management tively introduced modern management Science.

methods to China and taught them 


\section{Introduction: Why is Asia Pacific the Focus of Attention in the Business World Today?}

Yesterday's Asian economic miracle, in popular view, has turned overnight into today's economic disaster, threatening serious consequences for the whole world economy. The clear lesson is that we must go beyond simplistic diagnoses, positive or negative, and give serious attention to what is happening in the Asia Pacific economies.

\section{Asia Pacific Economies and Globalization}

To many it was perhaps inconceivable that the recent financial crisis of Asia Pacific could have triggered such financial turmoil in the West, and dragged the whole world economy to the edge of a deep recession. The effects of the Asian Pacific crisis have spread out to Europe and the USA. Asia Pacific corporations have cancelled outward investment. Asian demands of imports have fallen sharply with their deteriorating ability to pay for their purchases from Western countries and have driven companies in the West to downsizing or even to bankruptcy. The consequent currency devaluation and fall in wage costs in Asia Pacific will put more pressure on competitiveness and jobs in the developed West.
These developments bring home the fact that globalization is not some abstract theory, but a hard fact of economic life today. Globalization has led to the structural transformation of the present world system, creating new linkages and interconnections between states and societies. ${ }^{1}$ Firms and industries across the world have become more interdependent. Events, even decisions and activities, in one part of the world come to have significant consequences for some other actors in quite distant parts of the globe. In particular, the contemporary global financial system is one in which national markets throughout the world, though physically separate, interact together closely, often with dramatic consequences. ${ }^{2}$ That is why a financial crisis emerging in Thailand has come to spread not only to the

${ }^{1}$ Dunning, Johne H. 'Globalisation and FDI in Asian Developing Countries', in the Proceedings of the Second Conference on Global Change - The impact of Asia in the 21st Century, 6 \& 7 April 1998, Faculty of Management and Business, the Manchester Metropolitan University.

${ }^{2}$ Stopford, J. and Strange, S. (1991), Rural States, Rural Firms, Cambridge, Cambridge University Press. 
entire Asia Pacific region, but further to the West and the world generally.

It is clear that in the past two decades many Asia Pacific countries have participated in the trend towards a globalizing world economy. They are at the forefront of the globalization process, both inwards, attracting foreign investment and stimulating demands for imports, and outwards, exporting goods to and investing overseas. Apart from the increasing number of enterprises in the region that have been able to build up their capabilities to compete in the world market, Asia Pacific has an enormous population with rapidly rising purchasing power and constitutes an indispensable market for the rest of the world. Countries across the region are experiencing dramatic change cutting across every aspect of society: in people's everyday lives, in the cultures of a society, and in the politics of nations, as well as just their economic systems. These changes are in turn, visibly or invisibly, influencing the rest of the world.

The shock experienced by Asia Pacific and the West alike indicates that we have perhaps not yet fully recognized the extent of change which the globalization has brought to the world. Governments in Asia Pacific countries have not realized the significant changes to their culture and traditions following their integration with the rest of the world, especially the West, and that the values adopted by the new generation may differ sharply from those held by their predecessors. Conversely, in the Western world the understanding of development in Asia Pacific countries has been inadequate in many respects. 'The Far East' was far removed not just in terms of physical remoteness, but also in the levels of popular understanding and systematic academic enquiry. One example is the fact that the Asia-Pacific boom was still being called a 'miracle' when the region was on the very brink of collapse. As a result, policy makers in Western countries have not been properly equipped to deal with many essential issues arising in Asia Pacific countries. At the same time, firms from the West have been too ignorant of the operations of Asian Pacific economies and the changes that Asia business integration has brought about in the business world. Conversely, it is clear that firms in Asia Pacific have not sufficiently acquired the codes of business practice in the world, let alone their capabilities of technological innovation and productivity.

\section{The Emergence and Boom of Asia Pacific Economies}

Looking back over the past two decades or so, there is no doubting the important role of Asia Pacific countries in the development of the world economy. In a period when North America and West Europe were enduring prolonged economic stagnation, countries in the Asia-Pacific region began to boom. They showed surprisingly strong economic performance and became the driving force of the world economy in the process of recovering from recession. In the mid90 s, the region was regarded as the fastest-growing market of any size. Compared with the average GDP growth at $3.2 \%$ in North America and $2.6 \%$ in the European Union in 1995, in the Asia-Pacific region (excluding Japan), average GDP growth in 1995 
was $7.3 \% .^{3}$ The growth rate was far higher than in other developing regions, such as Latin America at $1.5 \%$, the Middle East and North Africa at 1.6\%, and Eastern Europe at 4.4\% in 1995.

The Asian economic 'miracle' took place in three or four historical phases. Japan emerged first. Its GDP was oneeighth that of the US before its economy took off at the end of 1950s. It overtook the European economies during the 1960s, and even now is still ranked with America as one of the two most powerful economies in the world. Then began the rise of four newly industrialized countries (NICs): Hong Kong, Singapore, South Korea and Taiwan, known as the four 'Asian tigers'. According to The World Competitiveness Yearbook 1998, Singapore ranks second after the US, and Hong Kong third, with Taiwan and Korea at sixteenth and thirty-fifth respectively. ${ }^{4}$ A larger group of countries, such as Malaysia, Thailand, Indonesia and the Philippines, have begun to follow step since the early 1970s. More recently China and Vietnam joined the tide. The AsiaPacific was like an escalator, with Japan at the top, followed by the second-, third- and fourth-stage countries and the like growing like a snowball, involving about 110 million people at the beginning and now half of the world's population.

The Asian economy is a microcosm of the global economy, embracing the

\footnotetext{
${ }^{3}$ 'Global economic forecasts: World growth/inflation prospects are good', Country Forecasts, 12 January 1996.

${ }^{4}$ The World Competitiveness Yearbook 1998, IMD, Lausanne, Switzerland, 1998.
}

most advanced and the still relatively backward. From the richest country, Japan, with GDP per capita US $\$ 40,161$, to the poorest countries in South Asia, with GDP per head of a couple of hundred US dollars, the gap is huge. But this allows richer countries like Japan and the NICs to push labour-intensive industries further into the countries which have lower labour cost. The NICs embarked upon the development process from low-cost economies based on labourintensive manufacturing, to include high-technology industries in both manufacturing and services. In replacing the role of NICs, third-wave countries rapidly caught up in many areas. For example, Malaysia has become the world's largest producer of air-conditioners and a leading exporter of telephone appliances and televisions. The Pearl Delta in Guangdong province of China is today the biggest manufacturing centre in the world. Before the financial crisis, Asia possessed a considerable proportion of the world industry: $30 \%$ of the world steel production; $60 \%$ of consumer electronics; $30 \%$ of computer output; and $35 \%$ of the vehicle output.

With respect to financial resources, the concept of 'poor Asia' is no longer true. According to both the UN and the World Bank reports, both America and Europe are small investors in the Asian miracle compared with the Asians themselves. ${ }^{5}$ Apart from affluent countries like Japan and NICs, a large number of the Asian Diaspora are sending their money back to the

\footnotetext{
5 'Has Europe failed in Asia?', The Economist, 2 March 1996.
} 
region. According to one report, ${ }^{6}$ some 55 million entrepreneurial overseas Chinese had been the main force behind the rapidly growing economy in the Asia-Pacific region. Although precise figures are difficult to assess, Asian experts conservatively estimate them to control several trillion US\$ in liquid assets. Also, the Asia-Pacific countries have higher domestic savings than the others. According to the 1996 Business Asia report, Singapore's gross domestic savings as a percentage of GDP were $48 \%$ and China's $40.5 \%$, ranking second and third in the world, with Indonesia, Thailand, Malaysia, Korea, Hong Kong, Japan and Taiwan all in the top $15 .^{7}$ Despite the financial crisis, the region possesses a considerable reservoir of capital.

\section{The Driving Forces}

Inbound investment by foreign institutions and individuals in Asia Pacific was one of the powerful engines of growth driving the economic boom. Since the early 1980s there has been a huge increase in inbound investment into Asia Pacific countries. Most noticeably, foreign direct investment in China has increased significantly. The growth of foreign direct investment in the region mirrors the strength and vitality of the internal capital market. It is estimated that three-quarters of all direct investment in the developing countries of Asia Pacific between

${ }^{6}$ 'The overseas Chinese', Fortune Vol. 130, No. 9, October 31, 1994.

${ }^{7}$ See note 3 .
1990 and 1995 originated from the region. $^{8}$

The changing atmosphere in the world politics of economy was another element which promoted investment from Western industrialized countries. Australian and North American countries have been encouraging interest in the Pacific Rim through the formation of the Asia-Pacific Economic Co-operation forum (APEC). European countries' investment in this region began to grow rapidly in the late 1980 s, and during the period 1988-1994 European trade with emerging Asia grew faster than its trade with Eastern Europe despite the opportunities arising from the collapse of the socialist block. This trend may have been pushed further by the grand summit of East and West in Bangkok in March 1996, where fifteen European leaders met with ten of their Asian counterparts.

In Asia-Pacific countries, the forceful yet market-friendly development strategies pursued by their governments have greatly increased incentives both in attracting inwards foreign direct investment and in promoting exports and outwards sourcing of technologies and markets. This inward investment at the same time perhaps sowed the seeds for the recent financial crisis because of the weak fiscal regulatory mechanisms in these emerging economies which were not able to effectively direct the investment, and instead nurtured speculative non-productive investment and concealed growing bad debts.

${ }^{8}$ UNVTAD (1997), World Investment Report: Transnational Corporations, Market Structure and Competition Policy, New York and Geneva, UN. 
Many have seen the emergence of the Asia-Pacific region as essentially an economic phenomenon. However, it could be suggested that this has arisen because economic development has been given the top priority by cultures in the region. For example, while the former Soviet Union sought a highly ideological route out of communism, China has followed a more pragmatic path - in a way that has made possible spectacular economic progress. In China, many 'Tiananmen Kids' turned to economic activities after the 1989 clash in Tiananmen Square and put off for the foreseeable future the prospects of democratic social reform. There is, however, some debate about the role of democracy. We have seen that Japan and Korea may be democratic, but their political systems work in a different manner from those in the West. Equally, China has secured economic growth without political pluralism. What seems to have been critical, in the aftermath of the Asia-Pacific crisis, is the existence of mechanisms for proper regulation and scrutiny, and the consequent ability to combat corruption and financial mismanagement.

Culture was perhaps another important factor behind the economic growth in the region. It is interesting to note a recent study of the so-called 'East Asian Miracle' by the World Bank, which turned up no magic formula, no single set of government policies. Its experts concluded that the key to the development is culture: people in these economies have simply studied harder, worked harder, and saved more than people in other countries. This conclusion may not be a comprehensive summary of the reasons for East Asian success, but it had a good grasp of the important characteristics of this regional phenomenon. A similar conclusion is drawn by Professor Gordon Redding, Director of the University of Hong Kong Business School. After many years of study in this area, he firmly believes that there are three successful forms of capitalism in Asia Pacific: Japanese, South Korean and Overseas Chinese. Although they are different from each other-because each is grounded in a different societal culture, and each has had its own political and economic history - they have been seen as the most dynamic sources of capitalism in the world. ${ }^{9}$

A wealth of studies demonstrate that Asia Pacific is enormously diverse. Despite this, they broadly agree on some common points. They flag some common cultural themes: an emphasis on basic material satisfaction for life and the importance of self-help, a belief in the duties and obligations of individuals, a strong commitment to social cohesion, a commitment to the family, a pragmatic view of the state and religion, a powerful belief in the value of education, and an appraisal of wealth and high achievement through hard work. This list of characteristics, which is not exhaustive, might be assumed as the cultural inheritance of the region, and that is likely to endure and persist from generation to generation.

Putting aside for a moment these conclusions on cultural origins of the region, which may be controversial, the most resilient phenomenon is the struggle and competition to create and capture wealth either among peoples

\footnotetext{
9 'Overseas Chinese Networks: Understanding the Enigma', Long Range Planning, Vol. 28, No. 1, 1995, pp.61-69.
} 
in each country or among nations over the Asian-Pacific Rim. For over a century, the West has been overwhelmingly dominant in the world's economy, politics and culture. In this period, other civilizations, including notably the Asian-Pacific, have been overshadowed and have performed relatively poorly. Despite this, there has been a continued belief by people from across this region in what they can achieve, backed up by a strong sense of past successes and glories. The success of Japan and the four Asian tigers have enhanced their confidence. The investment pool formed in the mid '90s in the Asia Pacific has provided a great opportunity for all countries in the region. This has encouraged countries' and people's high hopes and enormous appetite for change.

However, the imprudent haste with which peoples, firms and governments of Asia-Pacific countries competed to jump on the bandwagon of economic boom and share in its spoils has contributed to the current economic crises. The crises will certainly slow down the globalization process of Asia-Pacific countries. Despite this, if these countries and the region as a whole can retain social stability and retain and restructure their economic base, recovery is likely to be rapid. Indeed, the immediate repercussions of the crisis will be to cool down the overheated atmosphere of economic expansion and force through the restructuring of hitherto weak financial management and regulatory systems. This, together with an economic context that will force players to concentrate on restructuring their activities and regaining world competitiveness, will put economic development on more solid ground. In the longer term, the Asia-Pacific region is likely to remain the most dynamic force in the global economy.

\section{The Longer-Term Implications for the Business World}

With half the world's population moving rapidly along the road to industrialization and prosperity, the consequences may be profound. In the longer term the economic revolution in Asia Pacific can be expected to transform global activity of all kinds economic, political, cultural - and the environment. The pace of change in the world is accelerating. For instance, the industrialization which took Britain 150 years, for South Korea required a mere 30 years. Globalization has been reconstructing the world economy and politics. There has been a substantial relocation of manufacturing from the US and Europe to East Asia. The market for industrial goods which was once dominated by the West is moving East-wards. In the reverse direction, countries in the Asia-Pacific region have been dramatically increasing their scale of exports. In conjunction with this, an increasing number of companies are attempting to break into the US and European markets, following the lead of the Japanese. The recent economic crisis forces Asian firms to be even more competitive in their home and foreign markets.

The implications for the business world are at least threefold. First, as we have seen, under enormous pressure from the global reconstruction, more and more European companies are going abroad to search for markets 
and low costs of resources. At the same time, companies in the Asia-Pacific region have a need for capital, technologies and management skills. In relation to this, cross-cultural and cross-national management becomes more and more important. It is necessary for managers to change their mindset in order to fit the future trends.

Second, strategic management is crucial for companies in managing international business. Business strategies should be based on assessing internal strengths and weaknesses, understanding the external environment, and identifying potential opportunities and threats. As some future trends are foreseeable, whereas others are not, business strategy must be open to the performance of the entire business world. Business strategies therefore need to be adjusted over time to match the external and internal environment changes.

Third, it is necessary to improve general management skills in all aspects, in order to suit the business for an international dimension.

It is important to point out here that the rationale of today's business management is largely based on Western culture - Western values and the Western traditions of political and economic organization and legislative systems. Despite this, Western countries are still considered the appropriate models of doing business in the world, and Asian companies are copying them and significantly adapting their model in their own business environments. However, with the continuation of globalization, business models from Asia will grow, slowly but surely, and are likely to be increasingly influential.
Take Japan as an example. Japan has not intended to export its way of life. However, its impact on the Western world has been growing alongside its economic strength. This has been reflected in at least two ways: first, Japanese influence in the business world has grown through their new management and production systems (Just-In-Time, Total Quality Control and Lean Production) which are now de rigueur in many industries, especially in car manufacturing; and second, Japanese influence in people's lives is evident in a range of new consumer goods, especially electronic products such as computers and camcorders.

It is even possible that one day business contracts written in Chinese will be accepted by international business, just as readily as Englishlanguage contracts are today, as this is the language spoken by the largest population as a mother tongue. Where now young Asians are longing for liuxue (the Chinese expression for going to the West to study), perhaps young Europeans in the next generation will want to go to study in Asia Pacific. A knowledge of Asian cultures, Japanese or Mandarin, will be of growing importance.

Returning to practical issues today and in the very near future, the meaning of the Asia-Pacific transformation for business can be addressed to European and Asian companies in separate ways.

\section{Western Companies}

For Western companies, the most realistic and closely related question is, 'Can you afford to miss the market 
in Asia Pacific?' And if a company is seeking to be a player, no matter whether a strong or a marginal player in that market, then the next question is, 'How do you win that market?'

Can you afford to miss the market in Asia Pacific?

Given the size of their populations China 1.2 billion, Japan 125 million, plus other countries amounting to a total across the region of 2.9 billion population - can you, can any company, ignore this market? One may argue that, taking China as an example, population size does not properly represent the market size: of 1.2 billion Chinese, over $70 \%$ are peasants and most inland provinces are still poor. But, with the affluent Chinese coastal population alone, which equals only a quarter of the population, the number is as large as about 300 million, which is the entire population of EU countries. For instance, even though in 1995 Chinese average income per head was very low, merely about US\$ 450 , nevertheless because of the huge size, its adjusted purchasing power parity (international $\$$ at current prices and purchasing power parity) was US\$ 3,053 billion, ${ }^{10}$ ranked second after the US. Right now, this market can double the sales of a company of any kind, yours or your competitors'. If you decide to wait, your competitors may not - indeed, they may already be there.

${ }^{10}$ The World Competitiveness Yearbook 1996, IMD, June 1996, Lausanne, Switzerland.
Moreover, the population in Asia Pacific is growing, unlike some EU countries where the population today is shrinking. By the end of the decade, the population of the Asia-Pacific will rise from 2.9 billion to 3.2 billion. $^{11}$ If as forecast the adjusted purchasing power parity reaches US $\$ 10,000$ billion, the Asia Pacific market is sufficiently big to create or break a multinational. When this market has developed its full size, it may well alter the consumption trends of the world, including the markets in the West. We have witnessed that where once Europe and America dominated the markets for industrial goods, increasingly it must share them with others. During the 1970s and 1980s, Europe had to adjust to Japanese competition in domestic markets. Before the financial crisis, Korean companies had made a determined push into European markets. In the longer run, a renewed Asia economy with sounder capabilities and resources might well encourage many other countries in the region to follow suit. The message is clear. Only a niche marketing player can safely get away with ignoring the Asia Pacific.

How do you win in that market?

Perhaps the better question is, 'How do you avoid losing in that market?', especially during this period of slowdown of the world economy. This is still an immature market, and market demands for different products vary

11 'Global economic forecasts: World growth/inflation prospects are good', Country Forecasts, 12 January 1996. 
and change according to different phases of industrialization and the development of living standards and styles. If a company can sustain its operation platform in that market, even if does not gain very much in the short term, it will eventually profit one day.

In Asia-Pacific markets, the risks and rewards of involvement are both high. The relationships is between PRC, Taiwan and even Hong Kong remain uncertain. Tensions still exist between some countries, for example antipathy between South Korea and Japan. New wealth has brought domestic and new class tensions and exaggerated old ethnic anxieties inside countries. The increasing gap between the rich and the poor of individuals and regions has provoked concern in the central government in China. We have seen that the Indonesian government is increasingly vulnerable to the alienated urban poor. In addition, within the region long-term ethnic tensions have been refuelled by economic crisis (for example anti-Chinese sentiment in Southeast Asia, and especially Indonesia). The severe social unrest in Malaysia and Indonesia following their economic crises poses a serious obstacle to economic regeneration in their countries.

Asia-Pacific countries, in their economic system, legislative framework, market structures and value systems, are very different from the West. As we have mentioned above, business strategies are needed to win in this market, which should be built upon understanding of internal and external trends and accommodate short-term and long-term objectives. For European companies, there is an extra problem on top of these problems - that is, to assess this changing environment, its opportunities and threats, and to anticipate the future.

Many Western companies, especially multinationals, have been doing business in the Asia-Pacific region for many years. They have studied this market pretty carefully and have had more or less successful experiences. However, many tend to look at the changing Asia-Pacific environment in terms of Western perspectives. Successful ones tend to simplify the complexities of operating in Asia-Pacific countries and anticipate the future development trends according to the patterns that the Western countries have been through, while less successful ones tend to emphasize the problems, the primitive business culture, the rudimentary economic system and so on.

For Europeans, it is natural to look at the world from Western perspectives. However, this may mislead companies in assessing the changing external environment. For instance, there is a tendency for European or Americans to speculate that the younger generation of business people in Asia Pacific will become completely westernized. This is not necessarily correct. The older Asia-Pacific civilizations, which had initially failed to recognize the challenge posed by the Western economies and were thus eclipsed for more than a century, have eventually learned to admire Western scientific, technological and business developments. And they have begun to learn from this experience. So it is not accidental that with their heads down Asians have studied more European contemporary history than Europeans have the contemporary history of Asia. Now it is Europe's turn to face a new challenge. 


\section{Asian Companies}

For Asian companies, business today is no less tough than before. The current economic situation compels companies to rethink their future and position in the competitive world. Understanding the global reconstruction is also a big challenge. Companies who have benefited from the protectionism of local governments in the past are facing the challenge of a new business environment which is increasingly open to international competition. Therefore, competition in Asia-Pacific markets is intensifying. Apart from competing with companies from the West, companies in the Asia-Pacific region have to compete with a mushrooming number of local companies, as well as companies from other Asia-Pacific countries. Companies in less developed countries have to struggle very hard to overcome at least two key weaknesses: the lack of modern management skills, and low technologies.

Increasing competitiveness - to improve internal management

Competitiveness should be based on effective and sound general management. The low cost of local labour can be an advantage when competing in the international market for a short while, but it cannot sustain firms' competitiveness in the long term. Nor can low production costs make up for problems of other kinds stemming from poor product design, product quality, services, marketing, and the like. Usually, cheaper labour is associated with low skill and low technology, which certainly cannot meet fastchanging market demands. General management in many Asia-Pacific countries is still rudimentary. In particular, companies in countries like China and Vietnam, for example, have very limited knowledge and practices of modern management because of their previous socialist, centrally planned systems.

The lack of professional managers and skilled engineers is a big headache for Asian companies. Old ways of managing business are not suitable for today's fast-changing business environment. Adopting modern management merely by copying Western general management methods involves other problems, particularly in human resource management, as this is related to the particular philosophies, such as the values, beliefs, commitments and aspirations, of employees. Now, many indigenous companies have found it difficult to compete with multinationals and companies with substantial resources to recruit and retain experienced managers and engineers.

\section{Outsourcing - to learn from the West} and the best

In today's business world, competitiveness is also based on technological competencies. In this regard, Asian companies, including many in NICs, especially in less developed countries, are at very low level compared with Western industrialized countries. There is very little room for Asian companies to accumulate technological competencies by following the US or the other advanced countries step by step. First, the technological gap between the Western industrialized countries and less developed Asian countries is huge; and second, it is not necessary, in technological terms, 
for late-comers to go through all the stages that the Western companies have been through. A late-comer can benefit from bypassing as many unnecessary stages as possible.

There are many options whereby Asian companies can obtain advanced technologies from the West and the best. While capital is pouring into the Asia-Pacific Region, together with multinationals and Western companies, the activity of pursuing technologies can be carried out by technology transfer from, alliances with or even acquisition of companies within the region, or by investing in the industrialized world to get inside the technology pool. Many Japanese companies have been successfully operating in such a way, followed now by South Korean and many other companies.

\section{Conclusion}

In history, opportunity comes and goes. Seizing it you are a winner, missing it you are a loser. In addition, it may be misleading to look at today and tomorrow in the terms of the past. In ancient times competitive advantage lasted for centuries, today we are talking about decades or even less. The globalization and engagement of an increasing number of Asia-Pacific countries are bringing about substantial changes in the business world. There are great challenges for both European companies and Asian companies, though in different respects.
We need to look to the future with open minds and imagination, building our competitiveness upon a sound business management.

\section{About this book}

Twenty-eight cases have been selected for this book: they are arranged in three parts. Part I, Western Businesses in Asia Pacific, covers subjects such as seeking new potential in Asia Pacific, entering new markets, competing there, and more specifically handling local market attributes, labour relations, crises and ethical problems, and strategic planning for future external environmental changes.

Part II, Asian Businesses in Asia Pacific, are the cases of Asian companies competing in either domestic markets or other Asia-Pacific countries. They are competing on the basis of their internal management strengths, technological advantages and marketing skills.

Part III, Asian Businesses in Global Competition, highlights the subject of Asian companies actively involving in global competition, particularly in Western markets. Asian companies have been engaging in the global market for a variety of different reasons, some to obtain resources which they lacked in home countries, and some to expand markets following their successes in their domestic market. Some cases responded to the demands of European companies. 